\title{
Perancangan Sistem Autonomous pada Pesawat Model UAV Jenis Glider
}

(The Design of Autonomous System for a Glider Unmanned Aerial Vehicle Model)

\author{
Azhim Asyratul Azmi ${ }^{\mathrm{a}}$, Wahyudi ${ }^{\mathrm{b}}$ \\ ${ }^{a, b}$ Program Studi Teknik Mesin, Fakultas Teknik, Universitas Muhammadiyah Yogyakarta \\ Jl. Brawijaya, Tamantirto, Kasihan Bantul, Yogyakarta, Indonesia, 55183 \\ Telephone (0274) 387656/ fax (0274) 387646 \\ e-mail: azhim.asyratul.azmi@umy.ac.id, wahyudi_stmt@yahoo.co.id
}

\begin{abstract}
Abstrak
Pesawat model jenis glider merupakan pesawat model yang mampu terbang dangan kecepatan rendah dan memiliki efisiensi tinggi dalam penggunaan sumber daya tenaga, sehingga banyak digunakan untuk misi pemantauan. Keterbatasan utama misi pemantauan menggunakan pesawat glider adalah jarak pandang pilot. Untuk mengatasi kemapuan jarak pandang pilot yang terbatas dan meningkatkan luas area pemantauan, pesawat harus dapat terbang secara mandiri atau autonomous. Pesawat yang terbang secara autonomous dikenal sebagai Unmanned Aerial Vehicle (UAV). Penerapan sistem autonomous pada pesawat model jenis glider dilakukan dengan mengimplementasikan perangkat autonomous berupa flight controller, GPS, software GCS, dan telemetri. Perangkat autonomous diimplemantasikan pada pesawat model solfix yang disesuaikan terhadap spesifikasi pesawat. Flight controller yang digunakan adalah Arduflyer 1.5 dengan metode pemberian parameter atur yang dilakukan dengan pendekatan eksperimen uji terbang. Waypoint uji terbang berbentuk persegi panjang dengan lebar $90 \mathrm{~m}$ dan panjang $100 \mathrm{~m}$. Nilai parameter atur diperoleh dari observasi yang dilakukan pada pergerakan pesawat ketika automode hingga mampu terbang mengikuti waypoint yang telah ditentukan. Pesawat model solfix yang mampu terbang secara autonomous dengan stabil melewati waypoint yang ditentukan dengan perameter atur: RLL2SRV $P=1,5$; RLL2SRV $D=0,1$; PTCH2SRV $P=1,5$; PTCH2SRV D $=0,12 ;$ YAW2SRV_RLL=1,0; YAW2SEV_DAMP=0,3; dan Rudder Mix=0,250.
\end{abstract}

Kata Kunci: UAV, Glider, Arduflyer, Autonomous System

\begin{abstract}
Glider model airplane is an aircraft model with low speed cruising capability and high energy efficiency, widely used for observation missions. The main problem of using glider model plane to observation missions is the limitation of pilot visibility. Glider model airplane must be able to fly autonomously that also known as Unamanned Aerial Vehicle (UAV) to increase observation area futher. Implimitation of autonomous system on glider model airplane can be carried out by applying flight controller, GPS, GCS software and telemetry. Autonomous system was applied and adjusted to glider model airplane called Solfix. Arduflyer 1.5 Flight controller was used in this topic with flight test experimental approach to reach flight setup and tuning. Rectangle shape waypoint was set up with $90 \mathrm{~m}$ width and $100 \mathrm{~m}$ long. The flying set up and tuning was reached by observed airplane movement behavior on auto mode to follow the waypoint. Solfix model airplane was successfully flown on auto mode by following the waypoint with flight tuning: RLL2SRV_P=1,5;RLL2SRV_D=0,1;PTCH2SRV_P=1,5; PTCH2SRV_D $=0,12 ; Y A W 2 S R V \_R L L=1,0 ; Y A W 2 S E V \_D A M P=0,3$ and $R u d d e r$ Mix $=0,250$.
\end{abstract}

Keywords: UAV, Glider, Arduflyer, Autonomous System 


\section{Pendahuluan}

Pesawat model glider merupakan pesawat model fixed wing yang dirancang untuk dapat terbang dengan kecepatan rendah dan memiliki glide ratio yang tinggi. Penggunaan profil airfoil jenis low reynold dan aspect ratio sayap yang besar mengakibatkan pesawat model glider memliki gaya angkat yang maksimal walaupun terbang dengan kecepatan rendah. Tipe pesawat model jenis glider merupakan wahana terbang yang memiliki efisiensi tinggi dalam penggunaan sumber daya tenaga. Pesawat model jenis ini mampu terbang dengan jarak jelajah 200 meter dengan waktu terbang mencapai 30 menit [1].

Misi pemantauan menggunakan pesawat glider memiliki keterbatasan. Pilot sebagai pengendali pesawat memiliki keterbatasan jarak pandang sehingga untuk meningkatkan luas area pemantauan, pesawat harus dapat terbang secara mandiri atau biasa disebut dengan aotonomous yang kemudian dikenal sebagai Unmanned Aerial Vehicle (UAV). Penerapan sistem autonomous pada pesawat model glider akan meningkatkan efektivitas dan efisiensi pemantauan karena jalur penerbangan pesawat telah ditentukan sebelumnya. Untuk melakukan misi pemantauan, pesawat model UAV dapat diterbangkan sendiri atau secara beregu yang mampu meningkatkan keberhasilan misi [2]. Penggunaan pesawat model UAV mampu menggantikan kerja pilot sehingga dapat meminimalkan risiko korban jiwa ketika menjalankan misi berbahaya [3].

Sistem autonomous memiliki parameter atur yang harus diterapkan untuk menjadikan pesawat dapat terbang secara stabil. Parameter disesuaikan terhadap karakteristik pesawat dan misi yang akan dilaksanakan sehingga parameter atur selalu berbeda untuk setiap pesawat model dengan mengabaikan aeroelastisitas dan deformasi struktur sayap. Faktor aeroelastisitas dan deformasi struktur dapat diabaikan untuk pesawat model UAV dengan berat kurang dari $10 \mathrm{~kg}$, selama material yang digunakan komposit serat gelas atau serat karbon sebagai penguat sayap [4]. Nilai parameter atur dapat diperoleh dengan melakukan eksperimen secara langsung pada kondisi angin yang tenang. Hembusan angin yang kuat membutuhkan waypoint atau jalur penerbangan yang jauh untuk melakukan observasi terhadap pergerakan pesawat [5]. Setelah take off secara manual, kemudian dilanjutkan auto mode untuk menjalankan misi dan diakhiri dengan Return to Launch (RTL) dan landing [6]. Pengaplikasian sistem autonomous telah berhasil dilakukan oleh Guillaume Jouvet, dkk. (2019) yang menggunakan pesawat model UAV untuk melakukan misi pemantauan glasier dan gunung es [7].

\section{Metode}

Metode yang digunakan pada perancangan ini meliputi identifikasi masalah, studi pustaka, studi lapangan, pemilihan perangkat, dan pemasangan perangkat autonomous, serta uji terbang sebagai pendekatan eksperimen. Identifikasi masalah dilakukan berdasarkan keterbatasan jarak pandang pilot dalam menerbangkan pesawat model ketika melakukan misi pemantauan.

Identifikasi masalah pada penelitian ini menjadi dasar dalam menentukan perangkat autonomous. Selanjutnya, studi pustaka dilakukan sebagai referensi tentang perancangan sistem autonomous pada pesawat model. Studi pustaka juga dilakukan untuk mengetahui perangkat sistem autonomous yang harus digunakan serta mengetahui peraturan terkait penerbangan pesawat model UAV di Indonesia.

Studi lapangan dilakukan untuk mengetahui langsung spesifikasi pesawat model terkait dimensi fuselage, kecepatan jelajah pesawat, sumber daya tenaga pesawat, dan karakteristik terbang pesawat dalam menjalankan misi pemantauan. Pemilihan perangkat autonomous meliputi pemilihan flight controler, GPS, dan software Ground Control Station (GCS), serta telemetri untuk komunikasi pesawat terhadap GCS. Flight controller merupakan bagian utama dari sistem autonomous pada pesawat model UAV yang terdiri dari beberapa sensor yang berupa 3-axis accelerometer, magnetometer, dan gysroscope. Kalibrasi sensor wajib dilakukan sebelum melakukan uji terbang agar data yang diterima tetap akurat [8]. Joao Fortuna, dkk. (2013) menggunakan frekuensi wifi 5,0 GHz untuk transfer data status pesawat kepada GCS, tetapi pemilihan telemetri ditentukan oleh izin penggunaan frekuensi yang berbeda-beda di setiap negara [9]. Indonesia mengizinkan penggunaan frekuensi 900 $\mathrm{MHz}$ secara bebas dengan power maksimal 640 Watt [10]. 
Pesawat model jenis glider yang menjadi objek penelitian adalah pesawat model Solfix yang merupakan pesawat model glider. Solfix dirancang untuk keperluan pemantauan titik api kebakaran hutan seperti yang ditunjukan pada gambar 2.1. Studi lapangan yang dilakukan terhadap pesawat model Solfix diperoleh bahwa pesawat model Solfix memiliki wing span $1700 \mathrm{~mm}$ dengan panjang total pesawat $1450 \mathrm{~mm}$. Profil airfoil sayap menggunakan Eppler 668 dengan konfigurasi dihedral $15^{\circ}$ pada jarak $600 \mathrm{~mm}$ dari fuselage. Kecepatan terbang rata-rata 40-60 km/jam dengan waktu jelajah maksimum 15 menit penerbangan. Material pesawat menggunakan kayu balsa yang diperkuat dengan serat karbon pada bagian wing spar dan tail boom.

Fuselage pesawat model Solfix memiliki dimensi panjang $640 \mathrm{~mm}$, lebar $100 \mathrm{~mm}$, dan tinggi $140 \mathrm{~mm}$. Terdapat perangkat elektronik fuselage yang terdiri dari receiver, ESC, dan baterei pesawat sehingga fuselage memiliki sisa panjang $95 \mathrm{~mm}$ dan lebar $70 \mathrm{~mm}$.

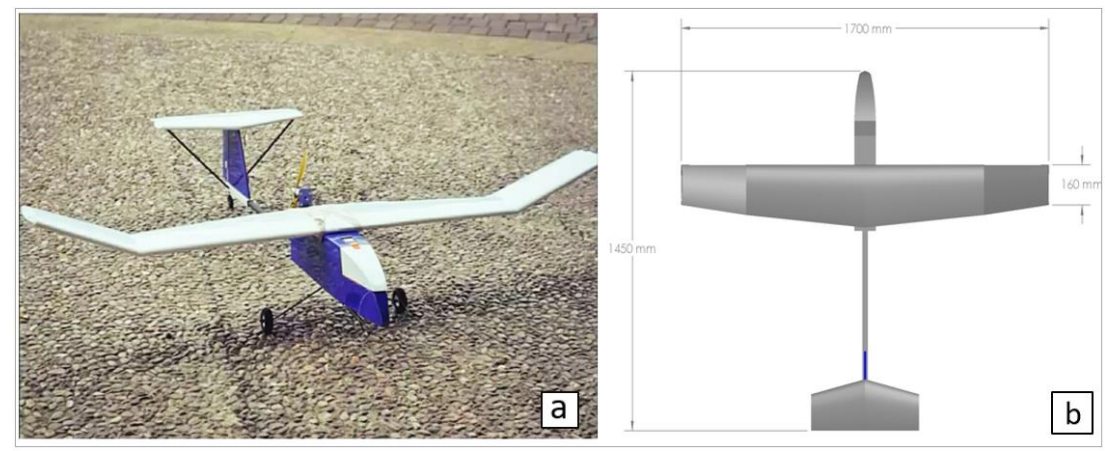

Gambar 2.1 (a) Pesawat model Solfix UAV; (b) Dimensi pesawat model Solfix UAV

Parameter atur menjadi kunci keberhasilan pesawat terbang yang stabil melalui jalur terbang atau waypoint yang telah ditetapkan sebelumnya. Parameter atur pada filght controller merupakan kontrol Propotional-Integral-Derivative (PID) yang mengatur respon suatu sistem instrumentasi dengan karakteristik adanya umpan balik pada sistem tesebut pada bidang kemudi pesawat. Adapun parameter atur pada perancangan ini adalah RLL2SRV_P dan D untuk bidang kemudi aileron yang mengatur roll pesawat. Parameter PTCH2SRV_P dan D untuk mengatur bidang kemudi elevator sebagai gerakan menukik pesawat. YAW2SRV_RLL dan DAMP untuk mengatur pergerakan rudder yang mengendalikan pergerakan yaw pesawat, serta Rudder mix yang digunakan untuk mengatur porsi dari kombinasi pergerakan rudder terhadap aileron.

Prosedur pemberian parameter atur dapat secara langsung ketika pesawat melakukan uji terbang melalui GCS dengan data yang ditransfer melalui telemetri. Alternatif pemberian parameter atur dapat dengan mendaratkan pesawat terlebih dahulu. Parameter atur awal akan menggunakan parameter atur default dari software GCS. Pesawat akan diterbangkan menggunakan mode manual, lalu ketika dirasa siap, mode penerbangan pesawat diganti menjadi auto mode. Auto mode merupakan mode penerbangan secara autonomous.

Pergerakan pesawat ketika terbang dengan auto mode kemudian diobservasi. Untuk pergerakan roll, nilai parameter atur default akan ditambah dengan skala 0,1. Ketika pergerakan masih terlalu lambat, penambahan akan selalu diberikan hingga pesawat dapat melakukan pergerakan roll yang diinginkan. Ketika pergerakan roll dirasa terlalu berlebihan, paramater atur default dapat diturunkan dengan skala penurunan 0,1 secara bertahap. Hal yang sama dilakukan untuk bidang kemudi lainnya. Pada perancangan ini, tingkat keberhasilan ditentukan oleh kemampuan pesawat yang mampu terbang stabil melalui waypoint.

\section{Hasil dan Pembahasan}

Perancangan sistem autonomous pada pesawat model Solfix meliputi pemilihan, pemasangan, dan pengujian perangkat autonomous. Perangkat sistem autonomous dipilih berdasarkan studi lapangan yang dilakukan terhadap psawat model Solfix. 
3.1 Pemilihan Perangkat Autonomous

a) Flight controller

Berdasarkan observasi yang dilakukan saat studi lapangan, pemilihan flight controller harus memiliki dimensi yang cukup untuk ditempatkan pada bagian fuselage pesawat model Solfix tanpa harus mengubah konstruksi dan bentuk dari pesawat tersebut, bagian fuselage yang tersisa memiliki panjang $9,5 \mathrm{~cm}$ dan lebar $7 \mathrm{~cm}$. Penempatan flight controller yang berada di dalam fuselage pesawat mengharuskan flight controller memilki sistem GPS dan telemetri yang terpisah agar GPS dan telemetri dapat ditempatkan di bagian luar fuselage untuk mendapatkan sinyal yang baik. Open source flight controller menjadi salah satu parameter pemilihan flight controller agar dapat dihubungkan terhadap software autonomous yang beragam.

Berdasarkan parameter pemilihan perangkat, flight controller yang digunakan adalah jenis Arduflyer 2.5. Perangkat tersebut merupakan open source flight controller dengan dimensi panjang $6,6 \mathrm{~cm}$ dan lebar $4 \mathrm{~cm}$. Arduflyer 2.5 dapat ditempatkan pada fuselage pesawat model Solfix tanpa mengubah konstruksi pesawat tersebut. Arduflyer 2.5 juga dilengkapi dengan port koneksi GPS dan telemetri (Gambar 3.1)

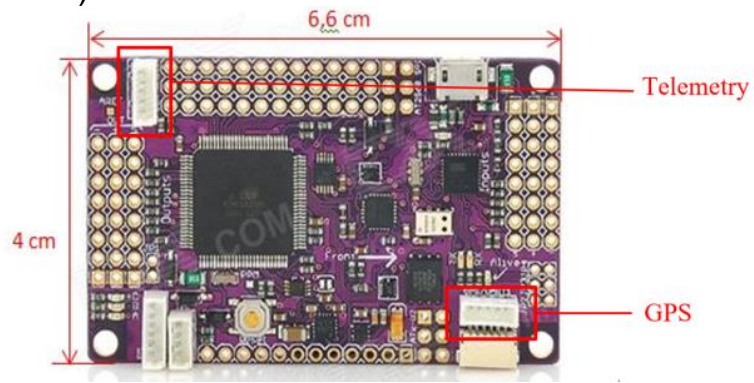

Gambar 3.1 Arduflyer 2.5 yang dilengkapi dengan port telemetri dan GPS yang terpisah

b) GPS

Pemilihan GPS sebagai media pemandu arah dan identifikasi lokasi pesawat ketika terbang akan disesuaikan terhadap spesifikasi Arduflyer 2.5. Parameter pemilihan GPS meliputi kesesuaian terhadap GPS port pada Arduflyer 2.5, jenis standalone GPS, dan built in antenna GPS. GPS yang dipilih pada perancangan ini adalah jenis CRIUS CN-06. Jenis GPS tersebut merupakan standalone GPS yang mampu bekerja langsung terhadap satelit tanpa membutuhkan jaringan internet. CRIUS CN-06 juga memiliki built in antenna berukuran $25 \times 25 \mathrm{~mm}$, dan memiliki GPS port jenis UART yang kompatibel terhadap Arduflyer 2.5 (Gambar 3.2).
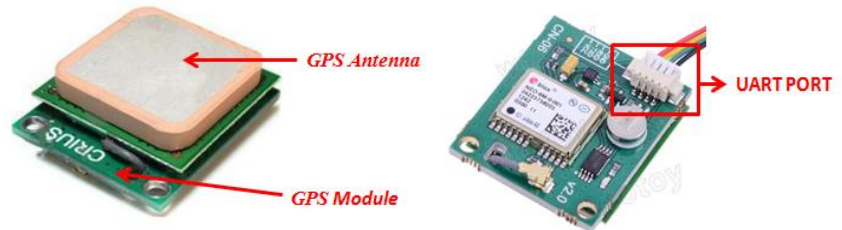

Gambar 3.2 CRIUS CN-06 memiliki built in antenna dengan UART port yang kompatibel terhadap Arduflyer 2.5

c) Telemetri

Parameter utama dalam pemilihan telemetri yang akan menghubungkan pesawat terhadap GCS adalah jarak. Pesawat model solfix dirancang untuk terbang dengan radius maksimal $5 \mathrm{~km}$ sehingga dibutuhkan telemetri yang mampu memberi dan menerima data hingga jarak tersebut. Pada perancangan ini, dipilih telemetri dengan jenis X-Bee Pro SB38 yang mampu melakukan transfer data 
hingga jarak maksimum $14 \mathrm{~km}$ (Gambar 3.3). X-Bee pro SB38 melakukan transfer data pada frekuensi $900 \mathrm{MHz}$.

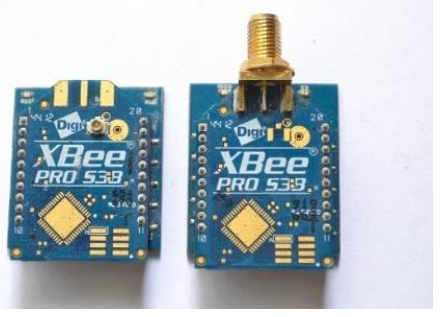

Gambar 3.3 Bee pro SB38

\section{d) Ground Control Station (GCS) Software}

Parameter pemilihan software GCS pada perancangan ini meliputi open source software, mampu menampilkan data pesawat, mampu menampilkan peta digital, dan memiliki fitur untuk pemberian parameter atur pesawat seperti yang ditunjukkan Gambar 3.4. Pada perancangan ini, software yang dipilih adalah Mission Planner. Software tersebut merupakan open source GCS software yang mampu menampilkan data pesawat melalui telemetri, menampilkan peta digital serta memiliki fitur untuk memberikan parameter atur pesawat. Mission planner juga memiliki fitur untuk menentukan waypoint pesawat sehingga jalur yang akan dilalui pesawat langsung diatur menggunakan peta digital.

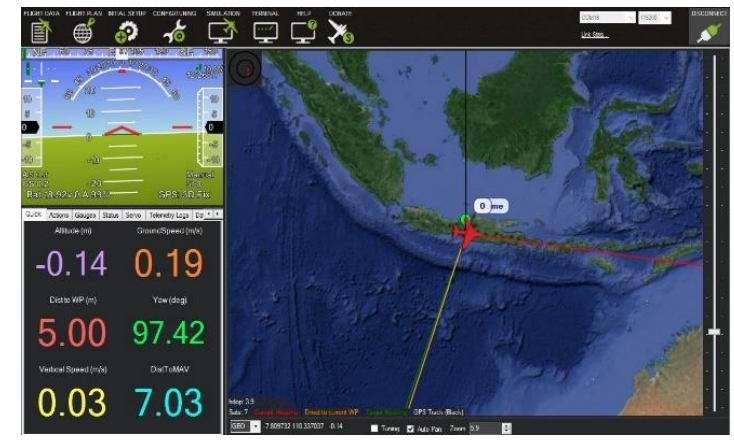

Gambar 3.4. Tampilan software GCS Mission Planner

\subsection{Pemasangan Perangkat Sistem Autonomous}

Pada tahap ini dilakukan pemasangan perangkat sistem autonomous yang telah dipilih pada pesawat model Solfix. Adapun skema pemasangan perangkat sistem autonomous pada pesawat model Solfix ditunjukkan pada Gambar 3.5.

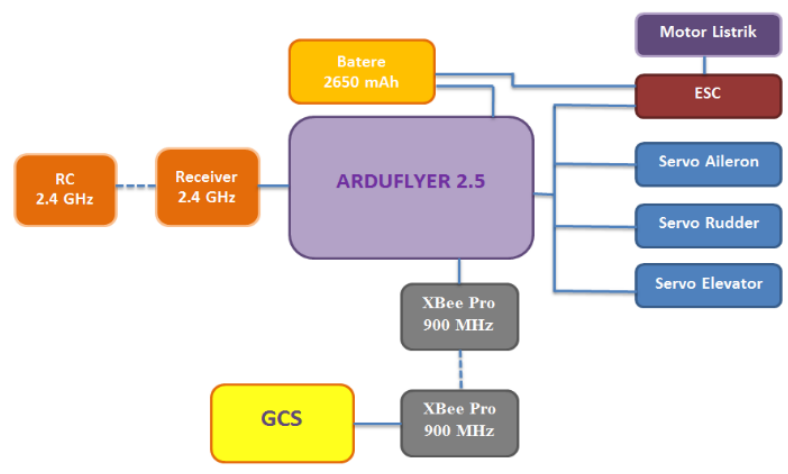

Gambar 3.5. Skema pemasangan perangkat sistem autonomous pada pesawat mode Solfix 
Pemasangan perangkat autonomous dimulai dengan pemasangan flight controler pada bagian fuselage pesawat. Arduflyer 2.5 yang telah dilakukan pemasangan enclosure kemudian ditempatkan pada fuselage bagian depan pesawat. Setelah terpasang, kemudian dilakukan penyambungan flight controller terhadap power module, ESC, receiver, dan servo penggerak bidang kemudi pesawat, seperti yang ditunjukkan pada Gambar 3.6.

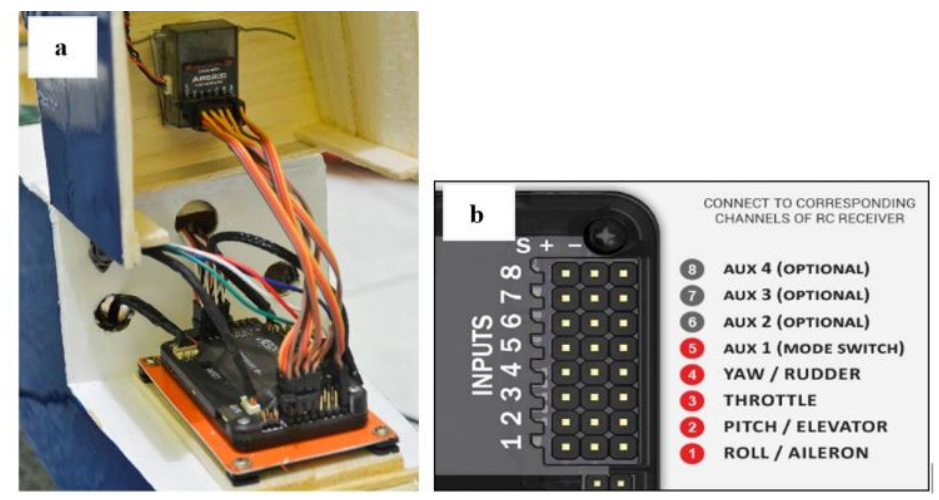

Gambar 3.6. (a) Flight controller yang merupakan sistem autonomous pesawat terpasang pada fuselage pesawat model Solfix; (b) Skema penyambungan flight controller terhadap bidang kemudi pesawat

Setelah flight controller terpasang, kemudian dilakukan pemasangan GPS. GPS ditempatkan diluar fuselage bagian atas dengan posisi antena menghadap ke langit (Gambar 3.7). Selanjutnya GPS dihubungkan terhadap fligt controller menggunakan kabel UART sepanjang $15 \mathrm{~cm}$.

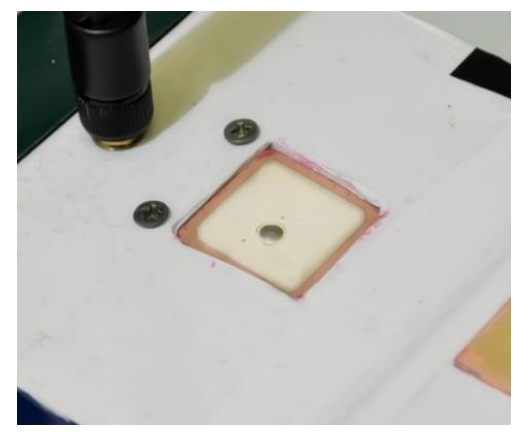

Gambar 3.7. GPS terpasang pada bagian atas fuselage pesawat model Solfix

Pada perancangan ini, telemetri ditempatkan di dalam fuselage bagian samping dan antena telemetry ditempatkan di bagian atas fuselage, seperti yang ditunjukkan pada Gambar 3.8. Hal ini bertujuan agar proses transfer data terhadap GCS menjadi lebih baik. Sementara itu, telemetri GCS dihubungkan terhadap komputer pada GCS melalui port USB dan terhubung langsung terhadap software GCS.

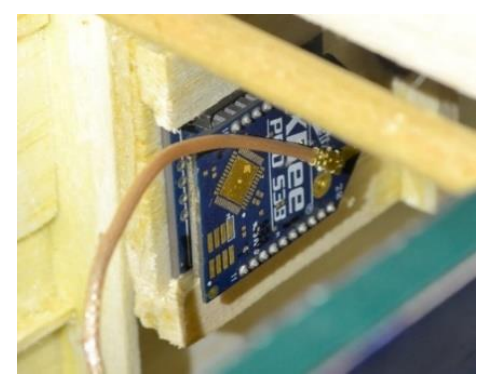

Gambar 3.8. Penempatan telemetri dan antena telemetri pada bagian fuselage pesawat model Solfix 
Uji terbang dilakukan untuk mengetahui semua perangkat bekerja dengan baik dan mampu menerbangkan pesawat model Solfix secara autonomous. Uji terbang dilakukan dengan memberikan waypoint sebagai jalur penerbangan pesawat seperti yang ditunjukkan pada Gambar 3.9. Ketinggian terbang $200 \mathrm{~m}$ dengan jarak rata-rata antar-waypoint $90 \mathrm{~m}$ dan $100 \mathrm{~m}$ membentuk persegi panjang.

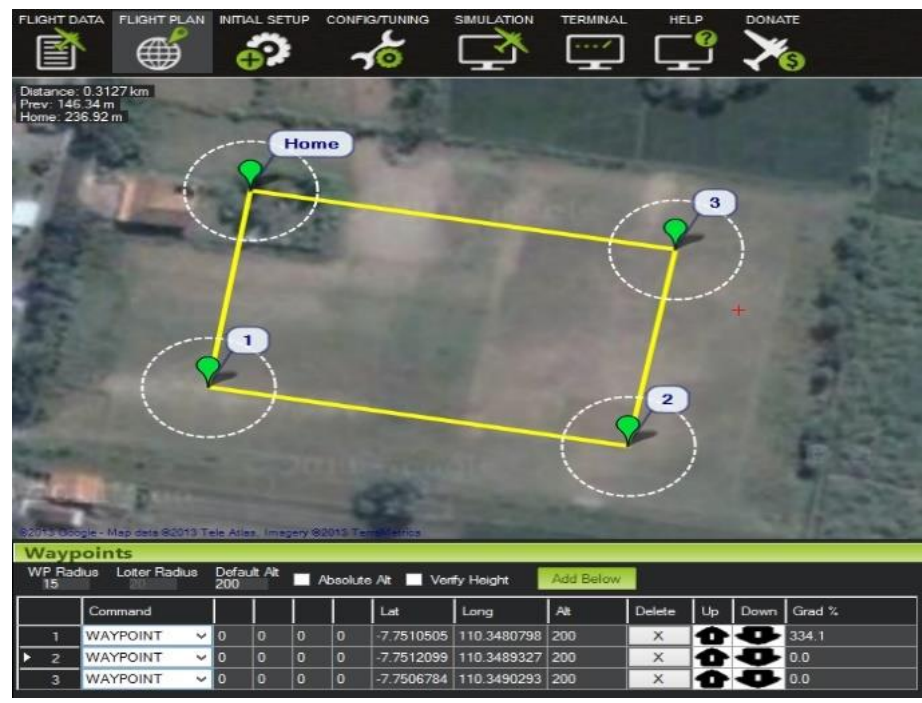

Gambar 3.9. Waypoint pengujian sistem autonomous pesawat model UAV

Sebelum melakukan uji terbang, dilakukan observasi terlebih dahulu terhadap semua bidang kemudi pesawat. Bidang kemudi pesawat harus dipastikan berfungsi dengan baik, seperti pergerakan aileron, rudder, elevator, dan motor pesawat. Pesawat melakukan take off dengan manual mode yang diterbangkan oleh seorang pilot. Setelah ketinggian mencapai $200 \mathrm{~m}$, automode yang merupakan mode penerbangan secara autonomous diaktifkan. Informasi pergerakan pesawat dilakukan dengan cara memantau langsung pergerakan pesawat ketika dalam automode. Pesawat dinyatakan terbang stabil apabila dapat terbang rata dan stabil menggunakan automode sesuai waypoint tanpa manuver diluar jalur waypoint.

Parameter atur awal yang digunakan adalah parameter default yang ditetapkan oleh software GCS. Parameter atur selanjutnya akan disesuaikan berdasarkan observasi terhadap pergerakan pesawat secara langsung. Uji terbang dilakukan hingga pesawat dapat terbang dengan stabil. Pemberian parameter atur pada uji terbang ini tidak bisa secara langsung melalui GCS karena kendala interferensi sinyal telemetri sehingga pesawat harus melakukan landing terlebih dahulu baru dilakukan perubahan parameter atur. Observasi terhadap pesawat dilakukan terhadap pergerakan roll, pitch, dan yaw. Pesawat model Solfix dapat terbang stabil secara autonomous dengan parameter atur, seperti yang ditunjukkan pada Tabel 3.1.

Tabel 3.1. Parameter atur pesawat model Solfix pada automode

\begin{tabular}{clccc}
\hline No. & Parameter Atur & Bidang Kemudi & $\begin{array}{c}\text { Parameter Atur } \\
\text { Default }\end{array}$ & $\begin{array}{c}\text { Parameter Atur } \\
\text { Solfix }\end{array}$ \\
\hline 1 & RLL2SRV_P & Aileron & 0,4 & 1.5 \\
2 & RLL2SRV_D & Aileron & 0 & 0,1 \\
3 & PTCH2SRV_P & Elevator & 0,4 & 1,5 \\
4 & PTCH2SRV_D & Elevator & 0 & 0,12 \\
5 & YAW2SRV_RLL & Rudder & 0,4 & 1,0 \\
6 & YAW2SEV_DAMP & Rudder & 0 & 0,3 \\
7 & Rudder Mix & Rudder dan Aileron & 0 & 0,250 \\
\hline
\end{tabular}




\section{KeSIMPULAN}

Perancangan sistem autonomous pada pesawat model glider dapat dilakukan menggunakan perangkat sistem autonomous yang terdiri dari flight controller, GPS, telemetri dan software GCS. Pemasangan perangkat autonomous pada pesawat model harus sesuai dengan spesifikasi pesawat dan sesuai pada tempatnya. Pesawat model jenis glider dapat terbang dengan stabil menggunakan automode sesuai waypoint yang telah ditentukan dengan melakukan observasi terhadap pergerakan pesawat secara langsung. Pemberian parameter atur harus dilakukan landing terlebih dahulu karena interferensi sinyal telemetri.

\section{Daftar Pustaka}

[1] Suroso Indreswari; Irmawan Erwhin. Analysis Of Aerial Photography With Drone Type Fixed Wing In Kotabaru, Lampung. Journal Of Applied Geospatial Information Vol 2 No 1. 2018.

[2] Fabio Augusto de Alcantara Andrade, et al. Autonomous Unmanned Aerial Vehicles in Search and Rescue Missions Using Real-Time Cooperative Model Predictive Control. MDPI. 2019.

[3] J. T. K. Pin, et al. Generic unmanned aerial vehicle (UAV) for civilian application-A feasibility assessment and market survey on civilian application for aerial imaging. IEEE Conference on Sustainable Utilization and Development in Engineering and Technology. 2012.

[4] D. Cadogan, et al. Inflatable and rigidizable wings for unmanned aerial vehicles. 2nd AIAA Unmanned Unlimited Systems, Technologies, and Operations. 2003.

[5] Pedro L. Jimenes, Jorge A. Silva; Juan S. Hernandez. Experimental validation of Unmanned Aerial Vehicles to tune PID controllers in open source autopilots. European Conference For Aeronautics And Space Sciences (Eucass). 2017.

[6] He Bin; Amahah Justice. The design of an unmanned aerial vehicle based on the ArduPilot. Journal of Science and Technology Vol.2 No 4. 2009.

[7] Guillaume Jouvet, et al. High-Endurance UAV for Monitoring Calving Glaciers: Application to the Inglefield Bredning and Eqip Sermia, Greenland. Frontier in Earth Science Vol. 7. 2009.

[8] Cherub Dim, et al. Novel Experiment Design for Unmanned Aerial Vehicle Controller Performance Testing. IOP Conference Series: Materials Science and Engineering. 2019.

[9] Joao Fortuna, et al. Using low cost open source UAVs for marine wild life monitoring Field Report. 2nd IFAC Workshop on Research, Education and Development Unmanned Aerial Systems. 2013.

[10] Direktur Jenderal Pos Dan Telekomunikasi. Keputusan Direktur Jenderal Pos dan Telekomunikasi Nomor : 193 /Dirjen/2005 Tentang Persyaratan Teknis Alat dan Perangkat Komunikasi Radio Microwave Link. Direktoran Jenderal Sumber Daya dan Perangkat Pos dan Informatika. 2005. 